\title{
Theoretical electron affinities of PAHs and electronic absorption spectra of their mono-anions
}

\author{
G. Malloci ${ }^{1,2}$, G. Mulas $^{1}$, G. Cappellini ${ }^{2,3}$, V. Fiorentini ${ }^{2,3}$, and I. Porceddu ${ }^{1}$ \\ 1 INAF - Osservatorio Astronomico di Cagliari - Astrochemistry Group, Strada n. 54, Loc. Poggio dei Pini, \\ 09012 Capoterra (CA), Italy \\ e-mail: [gmalloci; gmulas; iporcedd]@ca.astro.it \\ 2 Dipartimento di Fisica, Università degli Studi di Cagliari, Complesso Universitario di Monserrato, \\ S. P. Monserrato-Sestu Km 0,700, 09042 Monserrato (CA), Italy \\ e-mail: [giancarlo.cappellini;vincenzo.fiorentini]@dsf.unica.it \\ 3 INFM - Sardinian Laboratory for Computational Materials Science (SLACS)
}

Received 25 October 2004 / Accepted 8 November 2004

\begin{abstract}
We present theoretical electron affinities, calculated as total energy differences, for a large sample of polycyclic aromatic hydrocarbons (PAHs), ranging in size from azulene $\left(\mathrm{C}_{10} \mathrm{H}_{8}\right)$ to dicoronylene $\left(\mathrm{C}_{48} \mathrm{H}_{20}\right)$. For 20 out of 22 molecules under study we obtained electron affinity values in the range $0.4-2.0 \mathrm{eV}$, showing them to be able to accept an additional electron in their LUMO $\pi^{\star}$ orbital. For the mono-anions we computed the absolute photo-absorption cross-sections up to the vacuum ultraviolet (VUV) using an implementation in real time and real space of the Time-Dependent Density Functional Theory (TD-DFT), an approach which has already been proven to yield accurate results for neutral and cationic PAHs. Comparison with available experimental data hints that this is the case for mono-anions as well. We find that PAH anions, like their parent molecules and the corresponding cations, display strong $\pi^{*} \leftarrow \pi$ electronic transitions in the UV. The present results provide a quantitative foundation to estimate the fraction of specific PAHs which can be singly negatively charged in various interstellar environments, to simulate their photophysics in detail and to evaluate their contribution to the interstellar extinction curve.
\end{abstract}

Key words. astrochemistry - molecular data - molecular processes - ISM: molecules - ultraviolet: ISM - methods: numerical

\section{Introduction}

Free gas-phase polycyclic aromatic hydrocarbons (PAHs) in different charge and hydrogenation states are commonly thought to be an important component of the interstellar medium (ISM) (Duley \& Williams 1981; Léger \& Puget 1984; Allamandola et al. 1985; Henning \& Salama 1998). Such molecules have been hypothesized to efficiently absorb in the visible and ultraviolet spectral ranges, producing at least a subset of the Diffuse Interstellar Bands (Léger \& d'Hendecourt 1985; van der Zwet \& Allamandola 1985; Crawford et al. 1985; Salama 1999) and contributing to the extinction curve (Joblin 1992; Joblin et al. 1992; Li \& Greenberg 1997); they are furthermore believed to efficiently convert the absorbed energy in infrared emission in the so-called unidentifed infrared (UIR) bands (Léger et al. 1989; Allamandola et al. 1989; Salama 1999; Hudgins \& Allamandola 2004; Bakes et al. 2004).

Nowadays PAHs are seen as an intermediate stage between the gas and dust phases of the interstellar matter, i.e. large molecules or very small grains depending on the point of view, and, as such, they are included in some form in all interstellar dust models (Li \& Greenberg 1997; Draine 2003; Li 2004;
Draine 2004). PAHs could play an important role in the formation and evolution of prebiotic organic molecules (Ehrenfreund 1999; Bernstein et al. 1999, 2003).

However, despite intensive searches and some promising candidates (Foing \& Ehrenfreund 1994; Tulej et al. 1998; Salama et al. 1999; Ruiterkamp et al. 2002), to date no single, specific PAH has been identified with certainty in interstellar spectra. Tentative identifications of neutral pyrene and anthracene were recently proposed by Vijh et al. (2004) to account for blue fluorescence observed in the Red Rectangle.

In our ongoing effort to produce detailed simulations of the photophysics of specific PAHs (Malloci et al. 2003; Mulas et al. 2003), we are building a large database of molecular properties obtained in a uniform way using available quantum-chemical tools (Malloci et al. 2004), and using them as a basis to run Monte-Carlo models of their behaviour (Barker 1983; Mulas 1998; Joblin et al. 2002; Mulas et al. 2004).

PAHs are expected to exist in a wide variety of interstellar environments, in a complex statistical equilibrium of different charge and hydrogenation states (Omont 1986; Bakes et al. 2001a,b; Le Page et al. 2001, 2003). As such, any specific modelling of specific interstellar PAHs must take into 
account all the ionisation states which may be relevant for a given astronomical environment. Several studies suggested that negatively charged PAHs play an important role in interstellar clouds (Omont 1986; Lepp \& Dalgarno 1988; Salama et al. 1996; Dartois \& d'Hendecourt 1997; Bakes \& Tielens 1998; Bakes et al. 2001a,b), and they have thus been the subject of experimental (Szczepanski et al. 1995; Halasinski et al. 2000, 2003; Ruiterkamp et al. 2002) and theoretical (Du et al. 1993; Langhoff 1996; Hudgins et al. 2000; Dessent 2000; Bauschlicher \& Bakes 2000, 2001; Rienstra-Kiracofe et al. 2001, 2002; Gonzales et al. 2003; Hirata et al. 2003; Treitel et al. 2004) investigations.

The most relevant molecular parameters needed to model the photophysics of interstellar PAH anions are:

1. accurate electron affinities;

2. structural parameters and vibrational analysis;

3. electronic absorption cross-sections up to the Lyman limit.

The set of anionic PAHs for which all of the above data are simultaneously available is relatively small. In particular, neither theoretical nor experimental photoabsorption spectra above $\sim 3 \mathrm{eV}$ are available to date, to the best of our knowledge. The spectra of several PAH anions were taken by Shida \& Iwata (1973) in organic matrices of boron, and only very few measurements directly applicable to interstellar physical conditions, namely using matrix isolation spectroscopy (Szczepanski et al. 1995; Halasinski et al. 2000, 2003; Ruiterkamp et al. 2002) have been reported. Calculations of electronic excitation properties for $\mathrm{PAH}$ anions have been published for a few species and in a limited energy range (Halasinski et al. 2000, 2003; Hirata et al. 2003). This paper aims to provide a homogeneous, comprehensive database regarding points 1 and 3 for a large sample of PAHs, using well-known, established theoretical techniques.

We studied 22 molecules ranging in size from azulene $\left(\mathrm{C}_{10} \mathrm{H}_{8}\right)$ to dicoronylene $\left(\mathrm{C}_{48} \mathrm{H}_{20}\right)$. The PAHs considered cover an ample range of structures inside the two large classes of pericondensed and catacondensed species. Although noncompact PAHs are expected to be less stable than compact ones with the same number of benzenoid rings, we extended the present study to both classes, including also large linear molecules such as pentacene $\left(\mathrm{C}_{22} \mathrm{H}_{14}\right)$. With the exception of naphtalene $\left(\mathrm{C}_{10} \mathrm{H}_{8}\right)$, which is known not to exist as a bound anion (see e.g. Rienstra-Kiracofe et al. 2001), we considered the same 20 PAHs we had previously studied in their neutral and cationic form (Malloci et al. 2004), with the addition of azulene $\left(\mathrm{C}_{10} \mathrm{H}_{8}\right)$, containing a seven-membered ring, and the $\mathrm{C}_{13} \mathrm{H}_{9}$ and $\mathrm{C}_{19} \mathrm{H}_{11}$ radicals (Hudgins et al. 2001; Weisman et al. 2001). The sample of small to medium-sized PAHs presented in this study has the same size-distribution as the mixture used by Allamandola et al. (1999) to match the mid-IR spectrum of the Orion Bar. Although some studies show interstellar PAHs to be on average larger than these species (Boulanger 1999), we restricted ourselves to PAHs containing less than $\sim 50$ carbon atoms, since computational costs steeply increase for larger species. The complete set of molecules investigated, together with their orientation, are shown in Fig. 1.
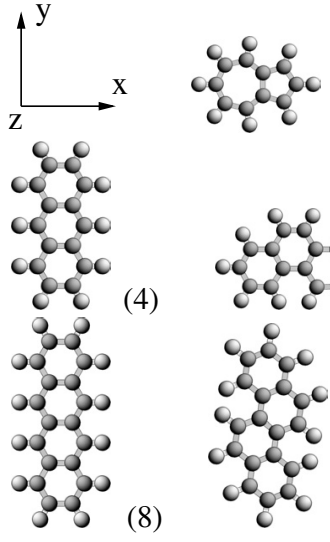

(1)

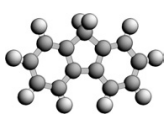

(2)
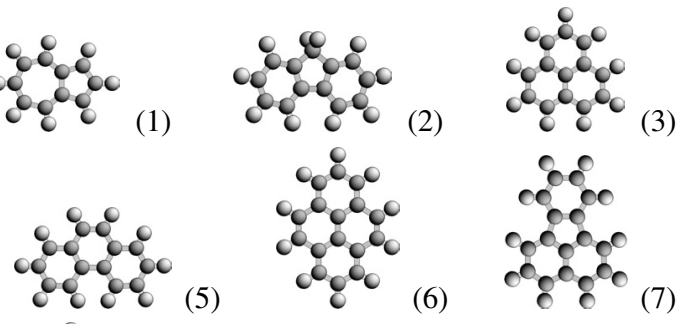

(6)
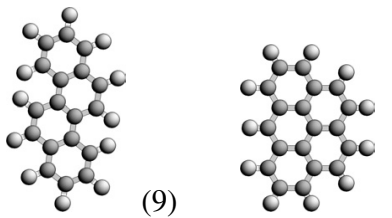

(10)

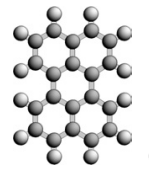

(11)
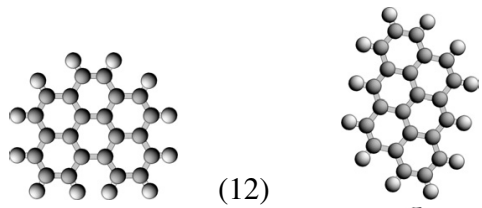

(12)

(13)
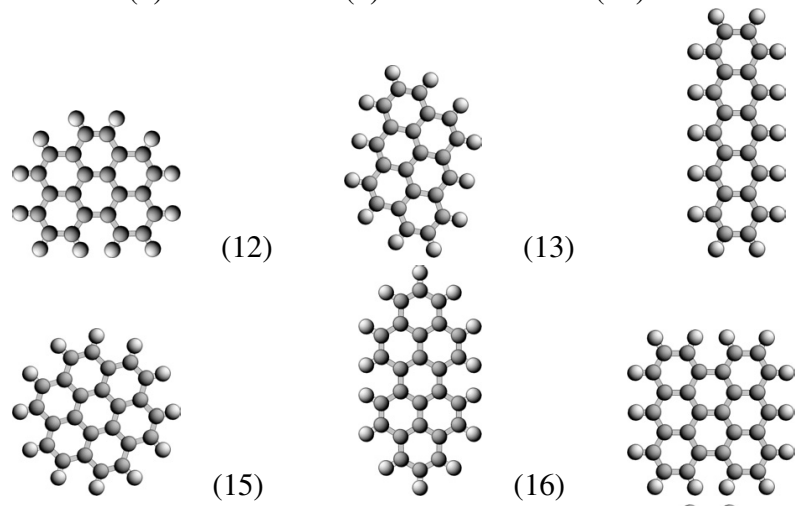

(16)

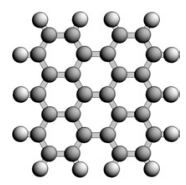

(15)
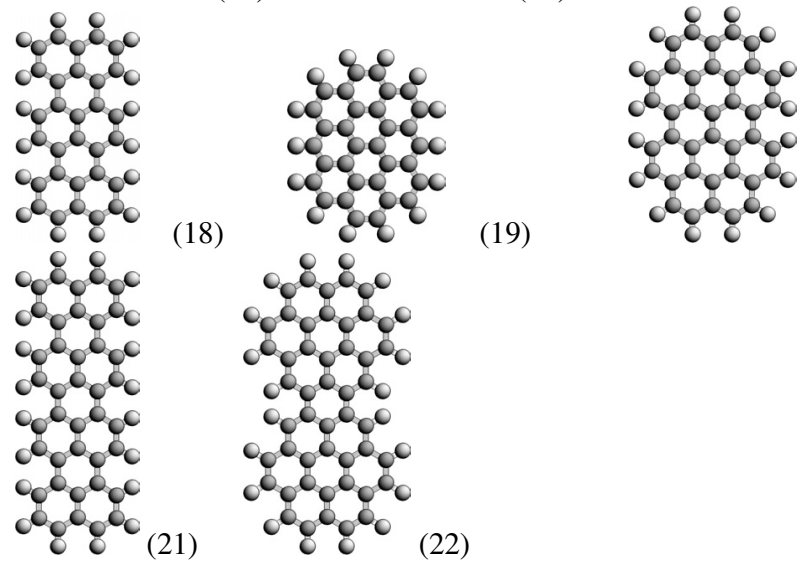

(19)

Fig. 1. Oriented structures of the PAHs investigated in this work: (1) azulene $\left(\mathrm{C}_{10} \mathrm{H}_{8}\right)$; (2) fluorene $\left(\mathrm{C}_{13} \mathrm{H}_{10}\right)$; (3) perinaphthenyl radical $\left(\mathrm{C}_{13} \mathrm{H}_{9}\right)$; (4) anthracene $\left(\mathrm{C}_{14} \mathrm{H}_{10}\right)$; (5) phenanthrene $\left(\mathrm{C}_{14} \mathrm{H}_{10}\right)$; (6) pyrene $\left(\mathrm{C}_{16} \mathrm{H}_{10}\right)$; (7) fluoranthene $\left(\mathrm{C}_{16} \mathrm{H}_{10}\right)$; (8) tetracene $\left(\mathrm{C}_{18} \mathrm{H}_{12}\right)$; (9) chrysene $\left(\mathrm{C}_{18} \mathrm{H}_{12}\right)$; (10) $\mathrm{C}_{19} \mathrm{H}_{11}$ radical; (11) perylene $\left(\mathrm{C}_{20} \mathrm{H}_{12}\right)$; (12) benzo[g, h, i]perylene $\left(\mathrm{C}_{22} \mathrm{H}_{12}\right)$; (13) anthanthrene $\left(\mathrm{C}_{22} \mathrm{H}_{12}\right)$; (14) pentacene $\left(\mathrm{C}_{22} \mathrm{H}_{14}\right)$; (15) coronene $\left(\mathrm{C}_{24} \mathrm{H}_{12}\right)$; (16) dibenzo[cd,lm]perylene $\left(\mathrm{C}_{26} \mathrm{H}_{14}\right)$; (17) bisanthrene $\left(\mathrm{C}_{28} \mathrm{H}_{14}\right)$; (18) terrylene $\left(\mathrm{C}_{30} \mathrm{H}_{16}\right)$; (19) ovalene $\left(\mathrm{C}_{32} \mathrm{H}_{14}\right)$; (20) circumbiphenyl $\left(\mathrm{C}_{38} \mathrm{H}_{16}\right)$; (21) quaterrylene $\left(\mathrm{C}_{40} \mathrm{H}_{20}\right)$; (22) dicoronylene $\left(\mathrm{C}_{48} \mathrm{H}_{20}\right)$.

In Sect. 2 we outline our computational approach and compare it with available experimental and theoretical data. In Sect. 3 we present our results and discuss their implications in the astrophysical context, mainly showing the relation between the contributions that neutral, cationic and anionic PAHs are expected to give to the interstellar extinction curve. Our conclusions are presented in Sect. 4, where the impact these kinds of 
studies may have for future space-based single-molecule identifications is outlined.

\section{Computational approach}

\subsection{DFT calculation of the electron affinities of PAHs}

The most direct method to evaluate the electron affinity of a molecule is to compute the difference between the total energies of the neutral and anionic states in their respective optimized geometries. While trivial in principle, if one uses localised basis functions to expand molecular orbitals this involves a significant effort especially for the anion, which requires the inclusion of diffuse functions (Dessent 2000; Rienstra-Kiracofe et al. 2001, 2002; Treitel et al. 2004). The total energies should include the zero-point vibrational energy (ZPE), which in the harmonic approximation is given by:

$E_{\mathrm{ZPE}}=\frac{1}{2} \sum_{i} \hbar \omega_{i}^{\mathrm{vib}}$

$\omega_{i}^{\text {vib }}$ being the $i$ th harmonic vibrational frequency of the molecule. We therefore computed total energies, equilibrium geometries and harmonic vibrational frequencies for the neutral and anion species of each PAH studied.

Several theoretical works showed that Density Functional Theory (DFT) (see e.g. Kohn 1999) can be successfully applied to study PAH anions. In particular, Dessent (2000) singled out a theoretical recipe which provides an accurate estimate of the adiabatic electron affinity of anthracene $\left(\mathrm{C}_{14} \mathrm{H}_{10}\right)$, the smallest unsubstituted PAH (in the strictest sense of the word) known to form a stable anion in the gas-phase. We therefore decided to extend this same approach to a large sample of PAHs to obtain both electron affinities and ground-state geometries.

With respect to the calculation of the vibrational properties, which we used here to account for ZPE corrections to the electron affinity, we performed the vibrational analyses according to well established theoretical prescriptions (Langhoff 1996; Bauschlicher \& Langhoff 1997; Hudgins et al. 2000, 2001; Bauschlicher \& Bakes 2000, 2001; Bauschlicher 2002).

For this part of the work we used the Gaussian-based DFT module of the NWChem computer code (Straatsma et al. 2003). More specifically, following Dessent (2000), we decided to use for this purpose the hybrid exchange-correlation functional B3LYP (Becke 1993) and the $6-31+\mathrm{G}^{*}$ Gaussian basis set including diffuse functions to expand the molecular orbitals. Although basis-set convergenge is not expected at this level, Dessent (2000) showed it to already yield quite an accurate result for anthracene $\left(\mathrm{C}_{14} \mathrm{H}_{10}\right)$, whose electron affinity was measured by anion photoelectron spectroscopy (Schiedt \& Weinkauf 1997a). Indeed, our results for perylene $\left(\mathrm{C}_{20} \mathrm{H}_{12}\right)$, coronene $\left(\mathrm{C}_{24} \mathrm{H}_{12}\right)$ and azulene $\left(\mathrm{C}_{10} \mathrm{H}_{8}\right)$, for which photoelectron spectroscopy data are currently available, are in excellent agreement with the experimental measurements by Schiedt \& Weinkauf (1997b), Duncan et al. (1999) and Schiedt et al. (2000) respectively, as well as with previous theoretical calculations (Rienstra-Kiracofe et al. 2001, 2002; Gonzales et al. 2003) performed for the perynaphtyl radical $\left(\mathrm{C}_{13} \mathrm{H}_{9}\right)$, fluorene $\left(\mathrm{C}_{13} \mathrm{H}_{10}\right)$ and tetracene $\left(\mathrm{C}_{18} \mathrm{H}_{12}\right)$ with the same level of theory. A detailed comparison is shown in Table 1 of Sect. 3.

The optimized ground state structures were planar with the exception of fluorene, and the corresponding molecular symmetry was assumed during calculations (e.g. $\mathrm{D}_{2 h}$ for ovalene, $\mathrm{C}_{2 v}$ for phenanthrene, $\mathrm{C}_{2 h}$ for chrysene, and so forth). In the case of the more symmetric coronene, belonging to $\mathrm{D}_{6 h}$ point group, the lifting of symmetry restrictions leads to optimized geometries with the lower symmetry $\mathrm{D}_{2 h}$, as expected from Jahn-Teller distortion (Kato et al. 1999; Weisman et al. 2003).

Due to the uncertainty of ZPE corrections to electron affinities (Dessent 2000; Rienstra-Kiracofe et al. 2001, 2002), the calculations of the harmonic vibrational frequencies needed to evaluate the ZPEs according to Eq. (1) were determined using for both neutral and anions the smaller basis set 4-31G, which has proven to provide accurate results for PAHs scaling all frequencies by the same empirical scale-factor (Langhoff 1996; Bauschlicher \& Langhoff 1997; Hudgins et al. 2000, 2001; Bauschlicher \& Bakes 2000, 2001; Bauschlicher 2002). To evaluate the impact of using a larger basis-set on the calculation of ZPE-corrections, in Table 1 we also report the results obtained using $6-31+G^{*}$ for the smaller species.

\subsection{The TD-DFT method applied to PAH anions}

Starting from the ground-state geometries obtained in the first step, we thereafter used the Time-Dependent Density Functional Theory (TD-DFT, Runge \& Gross 1984) to obtain the photoabsorption cross-sections of the stable mono-anions, again extending the approach we had previously shown to be reliable for neutral and cationic PAHs (Malloci et al. 2004). Given the lack of quantitative laboratory experiments on the photo-absorption properties of a large number of PAH anions up to the energy range excitable in the ISM, the use of theoretical quantum-chemistry appears to be the next best alternative. Indeed, TD-DFT calculations using different exchangecorrelation functionals and basis sets were shown to be a powerful tool to calculate electronic excitation properties for neutral PAHs (Heinze et al. 2000; Parac \& Grimme 2003) as well as radical ions up to large species (Hirata et al. 1999, 2003; Halasinski et al. 2000, 2003; Weisman et al. 2001, 2003). In particular, previous TD-DFT calculations for PAH anions (Halasinski et al. 2000, 2003; Hirata et al. 2003) were obtained with frequency-space implementations of TD-DFT, for which computational costs scale steeply with the number of required transitions, and were limited to the low-energy part of the spectrum.

In a previous work (Malloci et al. 2004) we calculated the electronic absorption spectra of 20 different PAH species and their cations in the framework of a real-time real-space implementation of TD-DFT. Such spectra were shown to be in good agreement with available experimental data (Joblin 1992; Joblin et al. 1992) and to be the second best choice for detailed modelling when laboratory measurements are missing (Mulas et al. 2004). The main drawback of this approach is that one does not obtain independent information for each excited state, 
Table 1. Electron affinities (in eV) of each PAH in our sample. For comparison, we list both adiabatic EA and ZPE-corrected values, including previous theoretical results and available experimental measurements.

\begin{tabular}{cccccc}
\hline \hline PAH & \multicolumn{2}{c}{ This work } & \multicolumn{2}{c}{ Published theoretical } & Published \\
molecule & adiabatic & ZPE-corrected & adiabatic & ZPE-corrected & experimental \\
\hline Azulene $\left(\mathrm{C}_{10} \mathrm{H}_{8}\right)$ & 0.63 & $0.75^{a} / 0.72^{b}$ & - & - & $0.7900 \pm 0.0080^{c}$ \\
Naphtalene $\left(\mathrm{C}_{10} \mathrm{H}_{8}\right)$ & -0.26 & $-0.07^{a} /-0.12^{b}$ & $-0.20^{d}$ & $-0.04^{d}$ & $-0.200 \pm 0.050^{e}$ \\
$\mathrm{C}_{13} \mathrm{H}_{9}$ radical & 1.25 & $1.33^{a} / 1.35^{b}$ & $1.29^{d}$ & $1.36^{d}$ & $1.07 \pm 0.10^{f}$ \\
Fluorene $\left(\mathrm{C}_{13} \mathrm{H}_{10}\right)$ & -0.31 & $-0.17^{a} /-0.18^{b}$ & $-0.31^{g}$ & $-0.14^{g}$ & - \\
Anthracene $\left(\mathrm{C}_{14} \mathrm{H}_{10}\right)$ & 0.53 & $0.66^{a} / 0.64^{b}$ & $0.58^{d}$ & $0.72^{d}$ & $0.5300 \pm 0.0050^{h}$ \\
Phenanthrene $\left(\mathrm{C}_{14} \mathrm{H}_{10}\right)$ & -0.05 & $0.10^{a} / 0.07^{b}$ & - & - & - \\
Pyrene $\left(\mathrm{C}_{16} \mathrm{H}_{10}\right)$ & 0.41 & $0.54^{a} / 0.53^{b}$ & - & - & - \\
Fluoranthene $\left(\mathrm{C}_{16} \mathrm{H}_{10}\right)$ & 0.72 & $0.97^{a} / 0.82^{b}$ & - & - & - \\
Tetracene $\left(\mathrm{C}_{18} \mathrm{H}_{12}\right)$ & 1.08 & $1.19^{a}$ & $1.13^{d}$ & $1.24^{d}$ & $1.067 \pm 0.043^{i}$ \\
Chrysene $\left(\mathrm{C}_{18} \mathrm{H}_{12}\right)$ & 0.29 & $0.44^{a}$ & - & - & - \\
C $19 \mathrm{H}_{11}$ radical & 1.55 & $1.62^{a}$ & - & - & - \\
Perylene $\left(\mathrm{C}_{20} \mathrm{H}_{12}\right)$ & 0.96 & $1.08^{a}$ & - & - & $0.9730 \pm 0.0050^{l}$ \\
Anthanthrene $\left(\mathrm{C}_{22} \mathrm{H}_{12}\right)$ & 1.05 & $1.17^{a}$ & - & - & - \\
Benzo[g, h, i]perylene $\left(\mathrm{C}_{22} \mathrm{H}_{12}\right)$ & 0.73 & $0.85^{a}$ & - & - & - \\
Pentacene $\left(\mathrm{C}_{22} \mathrm{H}_{14}\right)$ & 1.48 & $1.58^{a}$ & - & - & $1.392 \pm 0.043^{i}$ \\
Coronene $\left(\mathrm{C}_{24} \mathrm{H}_{12}\right)$ & 0.47 & $0.49^{a}$ & - & - & $0.470 \pm 0.090^{m}$ \\
Dibenzo[cd,lm]perylene $\left(\mathrm{C}_{26} \mathrm{H}_{14}\right)$ & 1.17 & $1.27^{a}$ & - & - & - \\
Bisanthrene $\left(\mathrm{C}_{28} \mathrm{H}_{14}\right)$ & 1.69 & $1.77^{a}$ & - & - & - \\
Terrylene $\left(\mathrm{C}_{30} \mathrm{H}_{16}\right)$ & 1.55 & $1.66^{a}$ & - & - & - \\
Ovalene $\left(\mathrm{C}_{32} \mathrm{H}_{14}\right)$ & 1.17 & $1.28^{a}$ & - & - & - \\
Circumbiphenyl $\left(\mathrm{C}_{38} \mathrm{H}_{16}\right)$ & 1.03 & $1.14^{a}$ & - & - & - \\
Quaterrylene $\left(\mathrm{C}_{40} \mathrm{H}_{20}\right)$ & 1.91 & $2.00^{a}$ & - & - & - \\
Dicoronylene $\left(\mathrm{C}_{48} \mathrm{H}_{20}\right)$ & 1.50 & $1.60^{a}$ & - & - & - \\
\hline
\end{tabular}

${ }^{a} \mathrm{~B} 3 \mathrm{LYP} / 4-31 \mathrm{G}$ value in this work.

${ }^{b} \mathrm{~B} 3 \mathrm{LYP} / 6-31+\mathrm{G}^{*}$ value in this work.

${ }^{c}$ Photodetachment photoelectron spectroscopy (Schiedt et al. 2000).

${ }^{d}$ B3LYP/DZP++ value from Rienstra-Kiracofe et al. (2001).

${ }^{e}$ Vertical attachement energy obtained by electron trasmission spectroscopy (Burrow et al. 1987).

${ }^{f}$ Laser threshold detachment (Gygax et al. 1979).

${ }^{g} \mathrm{~B} 3 \mathrm{LYP} / 6-31+\mathrm{G}^{*}$ value from Gonzales et al. (2003).

${ }^{h}$ Photodetachment photoelectron spectroscopy (Schiedt \& Weinkauf 1997a).

${ }^{i}$ Estimated from ion-molecule reaction equilibria (Crocker et al. 1993).

${ }^{l}$ Photodetachment photoelectron spectroscopy (Schiedt \& Weinkauf 1997b).

${ }^{m}$ Photodetachment photoelectron spectroscopy (Duncan et al. 1999).

such as the symmetry and description of the excited states, but only the direction of its transition dipole moment.

In the present paper we extend similar calculations to stable PAH mono-anions. We used TD-DFT as implemented in the Octopus computer program (Marques et al. 2003). The details of these calculations are almost the same as in Malloci et al. (2004), where a thorough description can be found. Here we only recall that in this code the time-dependent Kohn-Sham equations are solved in real time and the wavefunctions are represented by their discretised values on a uniform spatial grid. We performed all calculations using the widely used local-density approximation, specifically with the exchangecorrelation energy density of the homogeneous electron gas taken from Monte-Carlo calculations (Ceperley \& Alder 1980) and then parametrized by Perdew \& Zunger (1981).

With respect to Malloci et al. (2004) we here use a larger simulation box, to account for the more diffuse character of the electron density in the anions. Calibration calculations performed on the smallest species led us to choose box boundaries at least $4.5 \AA$ away from the nearest nuclei. We furthermore added a $1 \AA$ thick absorbing boundary, which quenches spurious resonances due to standing waves in the finite simulation box and mimics the effect of preionisation on the spectrum (Yabana \& Bertsch 1999; Marques et al. 2003). The positions of the nuclei were fixed at their ground-state geometry, as optimised in the previous step using NWChem. For a thorough description of the 0ctopus program and of its numerical aspects we refer the reader to Marques et al. (2003) and to the dedicated web site http: //www.tddft.org/programs/octopus.

\section{Results and discussion}

Table 1 lists both the adiabatic and the ZPE-corrected electron affinities, expressed in $\mathrm{eV}$, for our whole sample of molecules. We also included calculations for naphthalene $\left(\mathrm{C}_{10} \mathrm{H}_{8}\right)$, which is known not to form a stable anion, as a consistency check with published experimental and theoretical results. We calculated 
the ZPE corrections in the plain harmonic approximation, without scaling, since appropriate scaling factors for the anions are uncertain (Dessent 2000). Our adiabatic electron affinities are generally in very good agreement with available experimental measurements and with previous theoretical calculations. The addition of ZPE corrections actually makes things slightly worse both for our results and for previously published ones, in most cases. This is not unexpected, and has been previously studied and discussed by Rienstra-Kiracofe et al. (2001, 2002). Such corrections stem from the relatively small difference between the large calculated ZPEs of the anion and the neutral molecule. These differences arise due to the small changes in bond strength and/or geometry induced by the added charge. The general trend, especially when passing from closed-shell neutral PAHs to mono-anions, hence adding an electron in an anti-bonding $\pi^{*}$ molecular orbital, is in the direction of a weakening of the bonds, which is reflected in a slight increase in bond lengths. Harmonic vibrational frequencies accordingly tend to be slightly smaller, which in turn makes the ZPE correction to electron affinities positive for these species.

On the other hand, the added electron has a rather diffuse density, reaching out to relatively large distances from the nuclei; the asymptotic behaviour of the B3LYP functional (and most others) at large distances is known to be incorrect, and the binding energy of diffuse electrons will therefore be underestimated; this should translate into an underestimate of the adiabatic electron affinity.

Since this latter error and the error one makes neglecting the ZPE correction will be of opposite sign, they will tend to cancel each other to some extent. This may possibly explain why the calculated adiabatic electron affinities appear in better agreement with experiments than ZPE-corrected ones.

Moreover, while single harmonic vibrational frequencies calculated via DFT are usually considered rather good, with appropriate scaling, they are probably not quite accurate enough to reliably calculate differences of the order of $\sim 1 \%$ of their absolute values, which obviously tend to increase for larger molecules with more vibrational degrees of freedom.

The ZPE corrections we calculated with the larger 6-31+G* basis-set for the smaller species appear to be systematically slightly smaller than the ones calculated using the 4-31G (which goes in the direction of improving the agreement with experimental measures) and generally very close to the ones obtained e.g. by Rienstra-Kiracofe et al. (2001) with a vastly larger basis-set. In all cases, ZPE corrections appear not to grow for increasingly large molecules, remaining of the order of $\sim 0.10 \mathrm{eV}$. More investigations on the nature of the ZPE changes between neutral and charged PAHs are needed (see the discussion in Rienstra-Kiracofe et al. 2001).

Thus, with the exception of fluorene $\left(\mathrm{C}_{14} \mathrm{H}_{10}\right)$ and phenanthrene $\left(\mathrm{C}_{14} \mathrm{H}_{10}\right)$ which have electron affinity values near zero, for 20 out of 22 molecules under study we obtained electron affinity values in the range $0.4-2.0 \mathrm{eV}$, showing them to be able to accept an additional electron in their LUMO $\pi^{\star}$ orbital. In the case of chrysene $\left(\mathrm{C}_{18} \mathrm{H}_{12}\right)$ we calculated an adiabatic EA of $0.29 \mathrm{eV}$, which increases to $0.44 \mathrm{eV}$ upon inclusion of the ZPE correction. This set of values can be used for astrophysical modelling purposes, such as in approximate formulae for

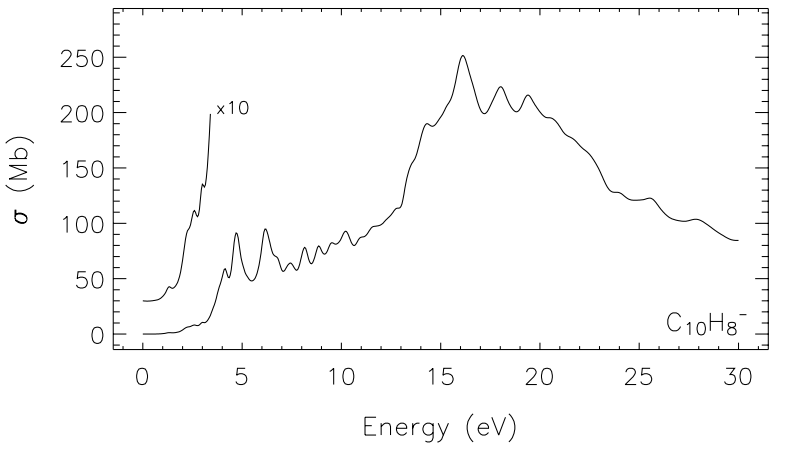

Fig. 2. Computed photo-absorption cross-section of azulene anion $\left(\mathrm{C}_{10} \mathrm{H}_{8}{ }^{-}\right)$. Units are megabarns $\left(1 \mathrm{Mb}=10^{-18} \mathrm{~cm}^{2}\right)$.

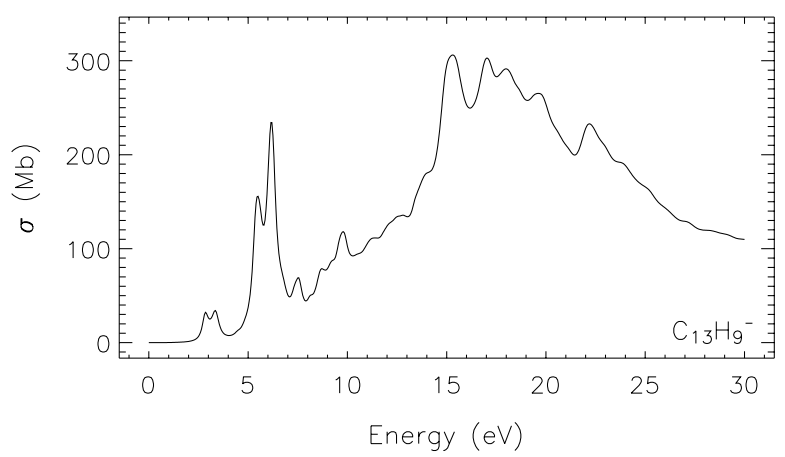

Fig. 3. Same as Fig. 2 for $\mathrm{C}_{13} \mathrm{H}_{9}{ }^{-}$.

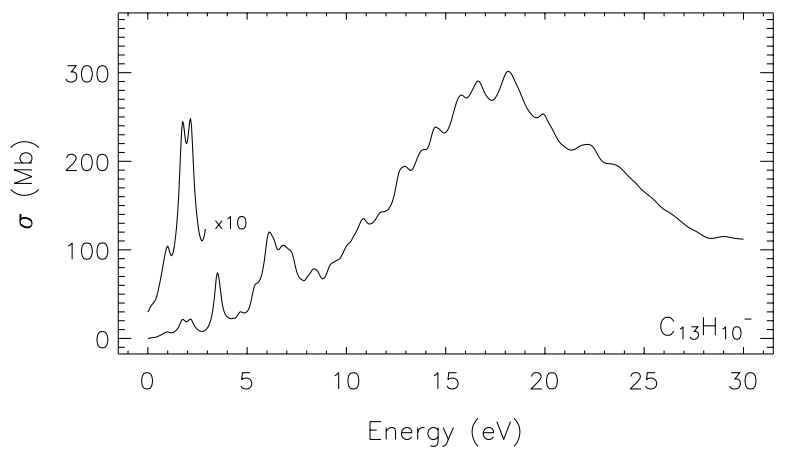

Fig. 4. Same as Fig. 2 for fluorene anion $\left(\mathrm{C}_{13} \mathrm{H}_{10}{ }^{-}\right)$.

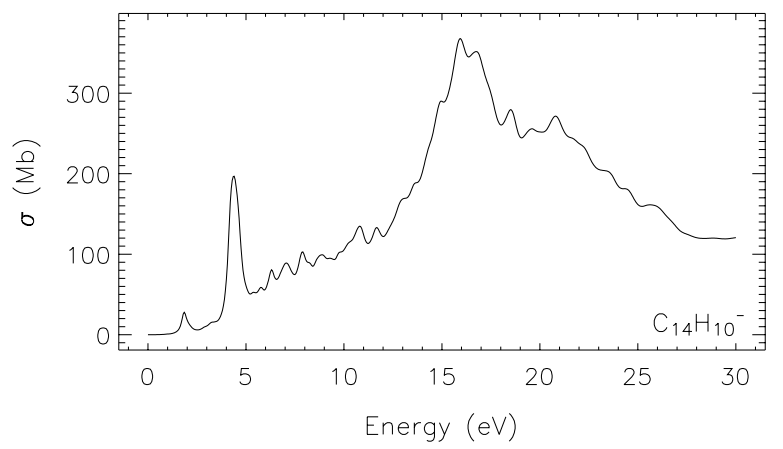

Fig. 5. Same as Fig. 2 for anthracene anion $\left(\mathrm{C}_{14} \mathrm{H}_{10}{ }^{-}\right)$.

the ionisation equilibrium of PAHs in interstellar environments (see e.g. Bakes et al. 2001a,b; Le Page et al. 2001, 2003).

For each PAH mono-anion in our sample, Figs. 2 through 23 present the computed photo-absorption spectra. 


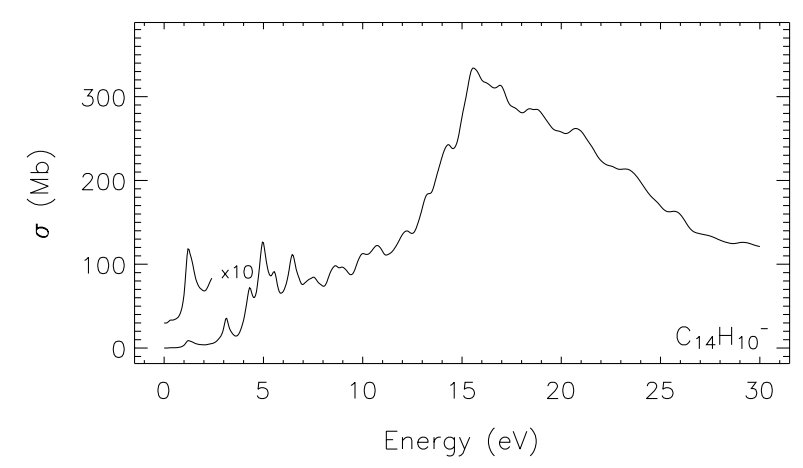

Fig. 6. Same as Fig. 2 for phenanthrene anion $\left(\mathrm{C}_{14} \mathrm{H}_{10}{ }^{-}\right)$.

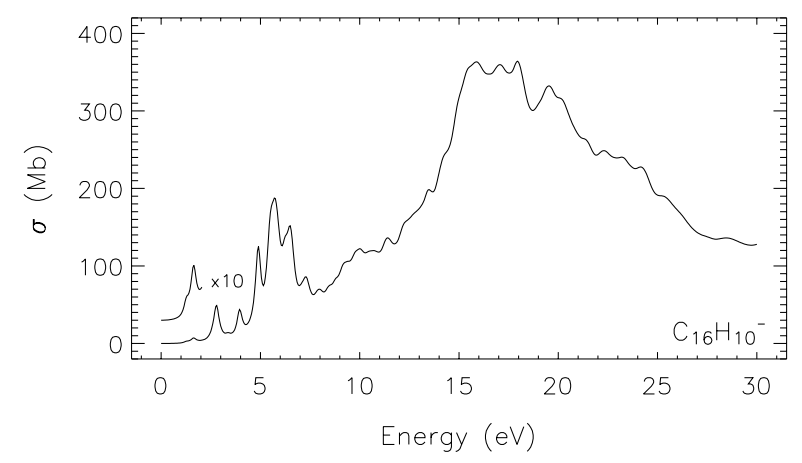

Fig. 7. Same as Fig. 2 for pyrene anion $\left(\mathrm{C}_{16} \mathrm{H}_{10}{ }^{-}\right)$.

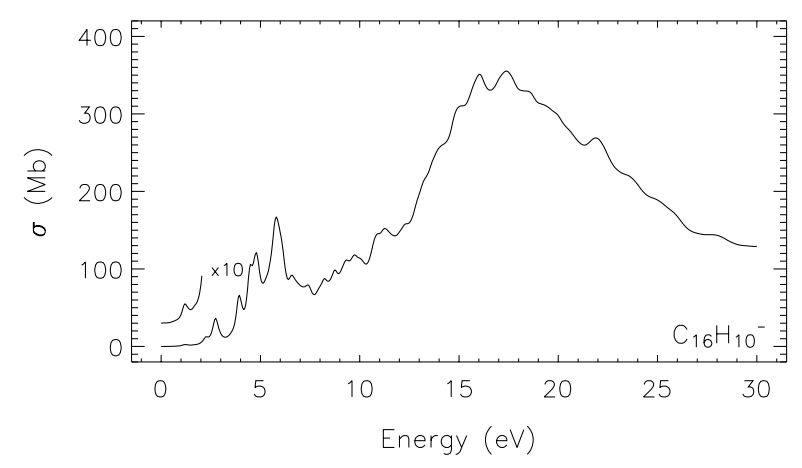

Fig. 8. Same as Fig. 2 for fluoranthene anion $\left(\mathrm{C}_{16} \mathrm{H}_{10}{ }^{-}\right)$.

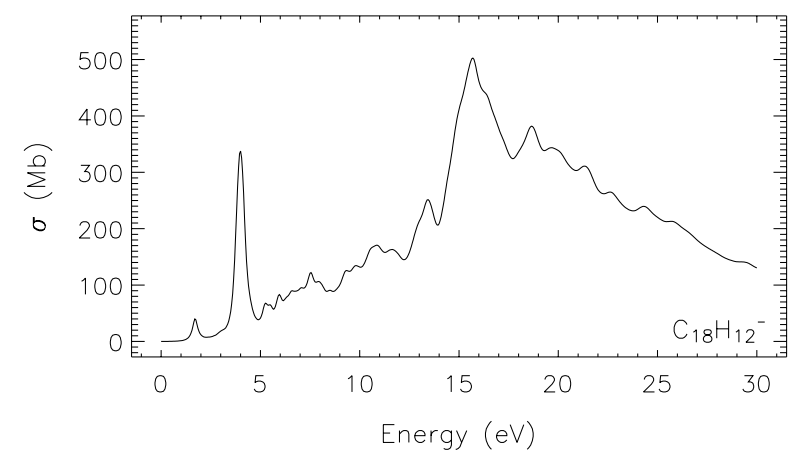

Fig. 9. Same as Fig. 2 for tetracene anion $\left(\mathrm{C}_{18} \mathrm{H}_{12}{ }^{-}\right)$.

Absorption cross-sections are expressed in megabarns $\left(1 \mathrm{Mb}=10^{-18} \mathrm{~cm}^{2}\right)$ and the spectra are displayed up to $\sim 30 \mathrm{eV}$. In particular, concerning the low-lying $\pi^{\star} \leftarrow \pi$ transitions occurring in the near-IR, visible and near-UV spectral range, Table 2 shows that the 0ctopus approach used here is as

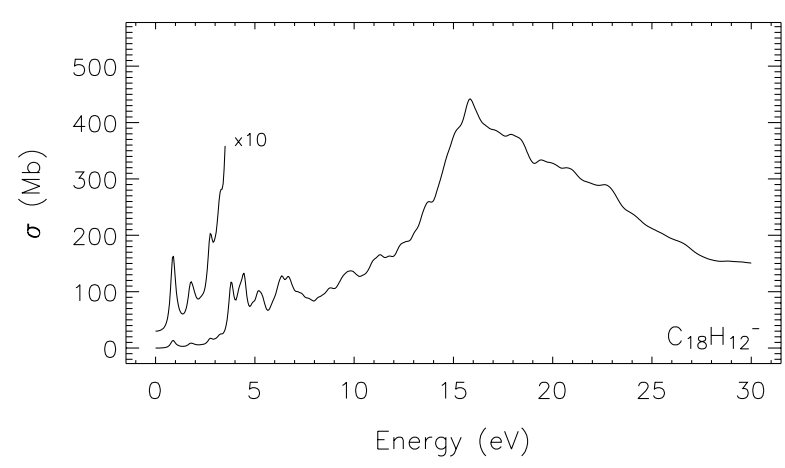

Fig. 10. Same as Fig. 2 for chrysene anion $\left(\mathrm{C}_{18} \mathrm{H}_{12}{ }^{-}\right)$.

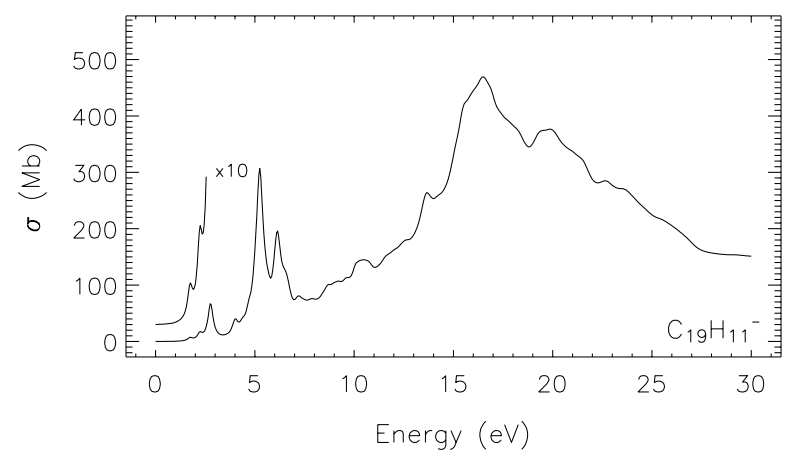

Fig. 11. Same as Fig. 2 for $\mathrm{C}_{19} \mathrm{H}_{11}{ }^{-}$.

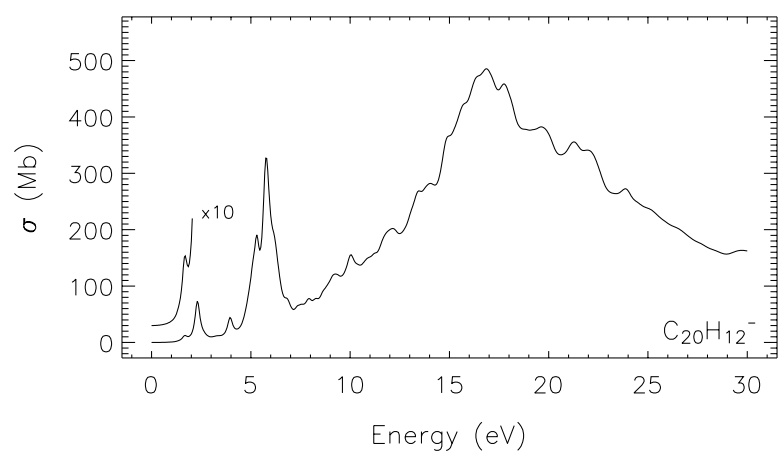

Fig. 12. Same as Fig. 2 for perylene anion $\left(\mathrm{C}_{20} \mathrm{H}_{12}{ }^{-}\right)$.

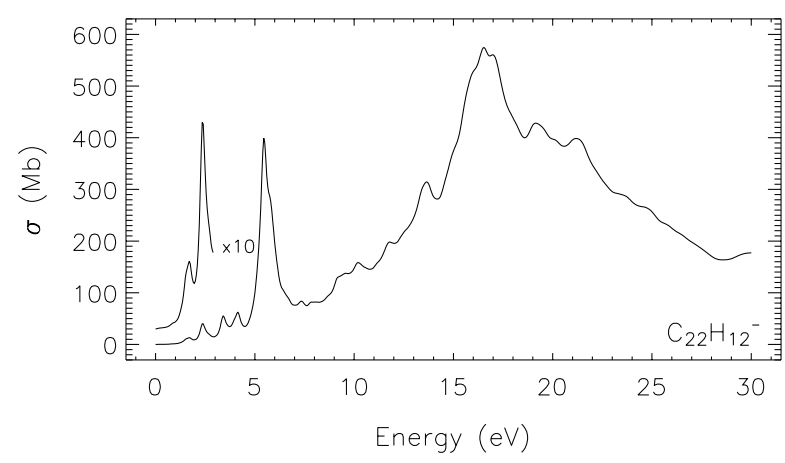

Fig. 13. Same as Fig. 2 for benzo[g, h, i]perylene anion $\left(\mathrm{C}_{22} \mathrm{H}_{12}{ }^{-}\right)$.

accurate as previously published theoretical results, compared to available experimental data. Computed vertical excitation energies are precise to within a few tenths of an $\mathrm{eV}$, which are indeed the typical accuracies of TD-DFT (Hirata et al. 1999, 2003). With respect to the corresponding oscillator 


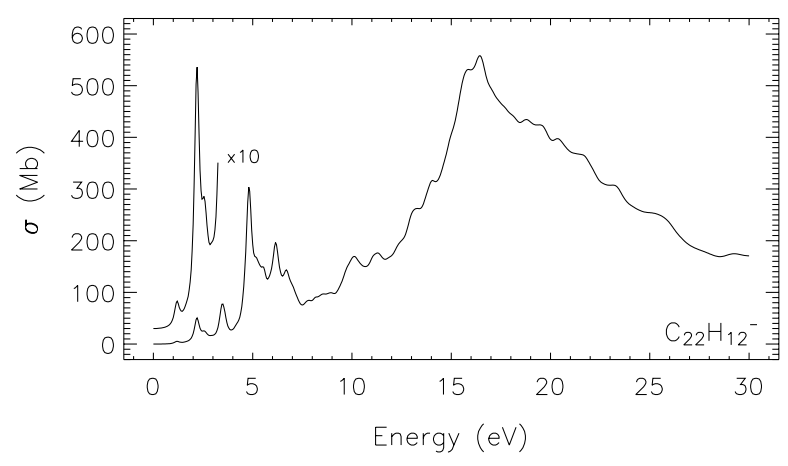

Fig. 14. Same as Fig. 2 for anthanthrene anion $\left(\mathrm{C}_{22} \mathrm{H}_{12}{ }^{-}\right)$.

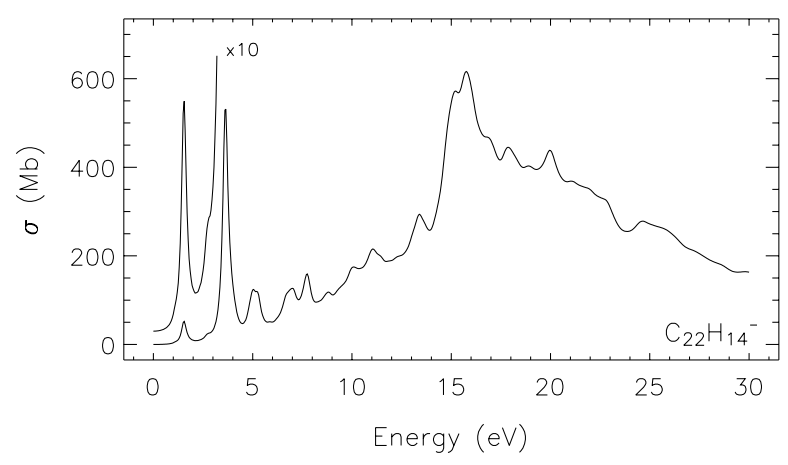

Fig. 15. Same as Fig. 2 for pentacene anion $\left(\mathrm{C}_{22} \mathrm{H}_{14}{ }^{-}\right)$.

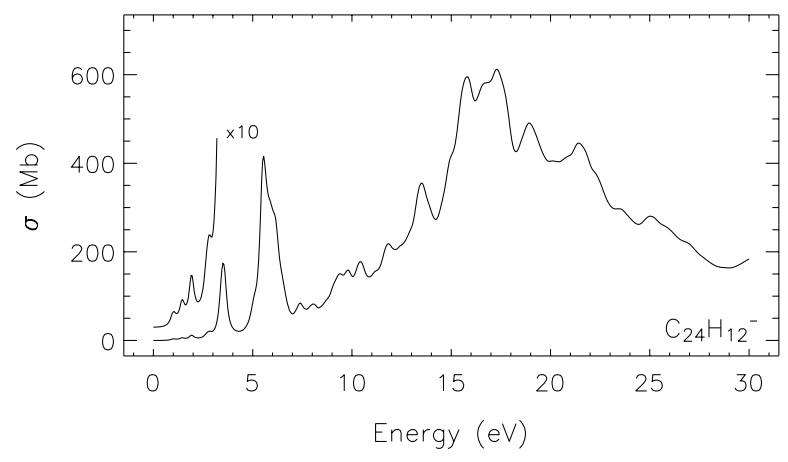

Fig. 16. Same as Fig. 2 for coronene anion $\left(\mathrm{C}_{24} \mathrm{H}_{12}{ }^{-}\right)$.

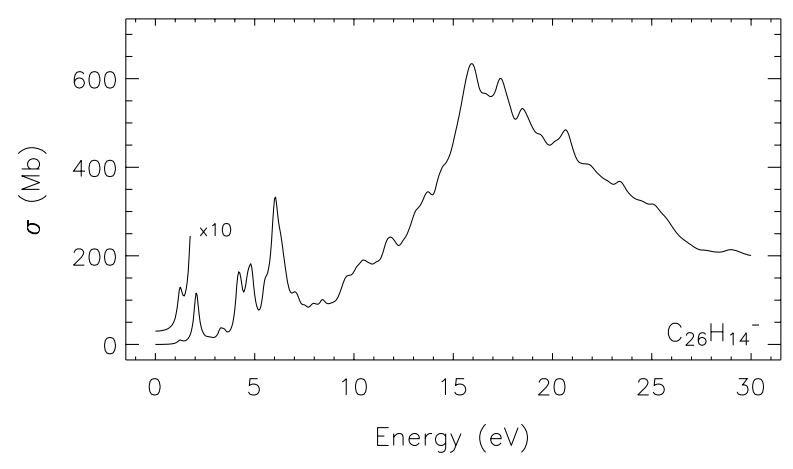

Fig. 17. Same as Fig. 2 for dibenzo[cd,lm]perylene anion $\left(\mathrm{C}_{26} \mathrm{H}_{14}{ }^{-}\right)$.

strengths, no experimental data for PAH anions are available to the best of our knowledge. We emphasise that while we firmly established the use of the TD-DFT implementation of Octopus to calculate accurate photo-absorption spectra of neutral PAHs through the visible and UV spectral

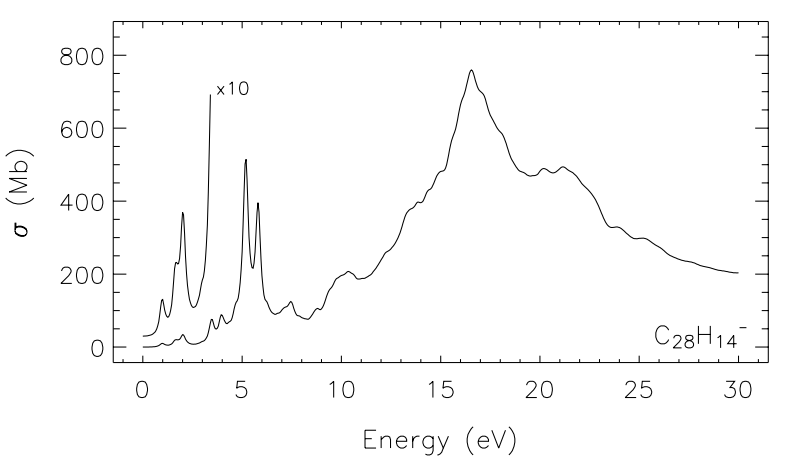

Fig. 18. Same as Fig. 2 for bisanthrene anion $\left(\mathrm{C}_{28} \mathrm{H}_{14}{ }^{-}\right)$.

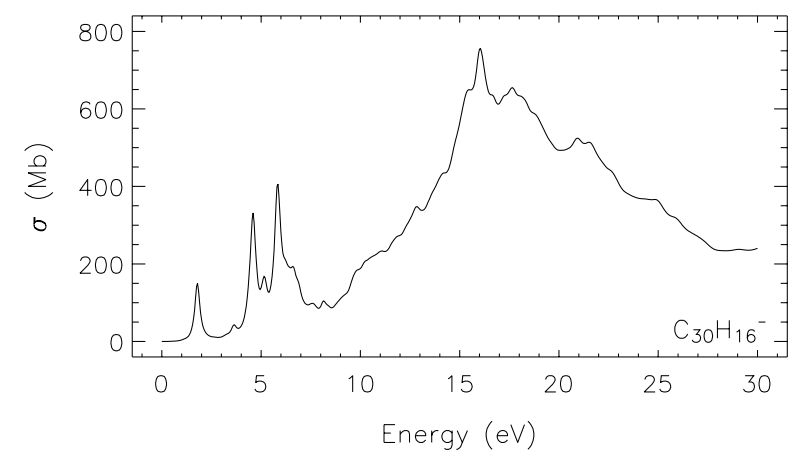

Fig. 19. Same as Fig. 2 for terrylene anion $\left(\mathrm{C}_{30} \mathrm{H}_{16}{ }^{-}\right)$.

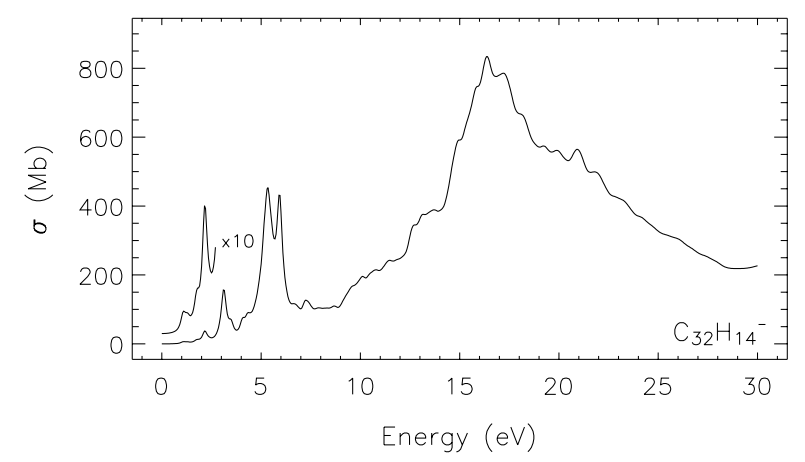

Fig. 20. Same as Fig. 2 for ovalene anion $\left(\mathrm{C}_{32} \mathrm{H}_{14}{ }^{-}\right)$.

(Malloci et al. 2004), experimental spectra in the far UV are needed for a similar direct validation for PAH ions.

These spectra can be compared with the previously calculated ones of the corresponding cationic and neutral PAHs (Malloci et al. 2004). One example of such a comparison is displayed in Fig. 24, which shows in a single plot neutral dicoronylene $\left(\mathrm{C}_{48} \mathrm{H}_{20}\right)$, its cation and its anion. The three spectra are very similar in the UV range, the anion and the cation being remarkably similar also in the visible. Such a behaviour has been previously discussed for the low-energy range by Halasinski et al. (2003) and Hirata et al. (2003), and is an expected consequence of the similarity in electronic structure of the first few electronic states of the cation and of the anion, and of the resulting first few electric dipole-permitted transitions.

This similarity is a general property throughout our sample and has an intriguing consequence regarding the UV range of the spectrum: apart from small details (e.g. the precise position of single, specific transitions of a single, specific molecule), 


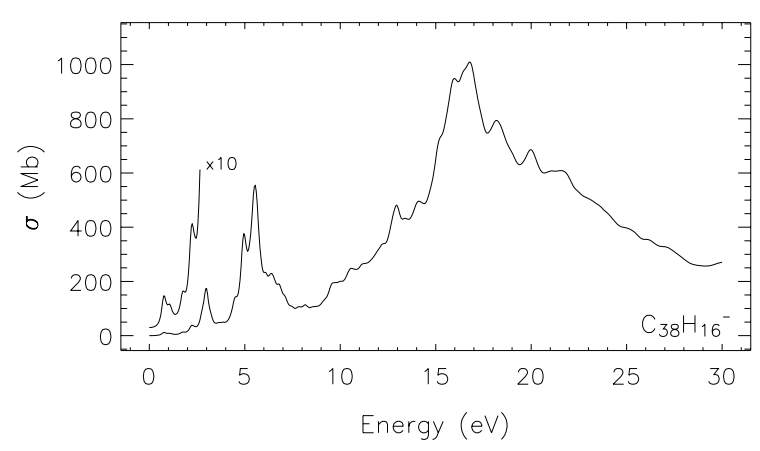

Fig. 21. Same as Fig. 2 for circumbiphenyl anion $\left(\mathrm{C}_{38} \mathrm{H}_{16}{ }^{-}\right)$.

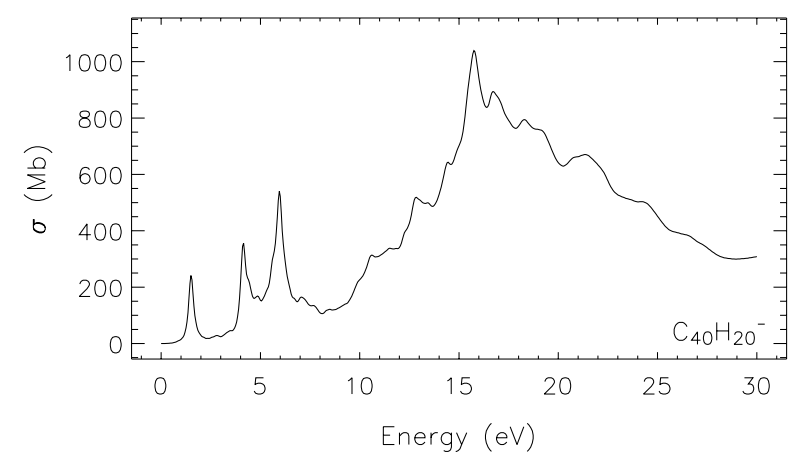

Fig. 22. Same as Fig. 2 for quaterrylene anion $\left(\mathrm{C}_{40} \mathrm{H}_{20}{ }^{-}\right)$.

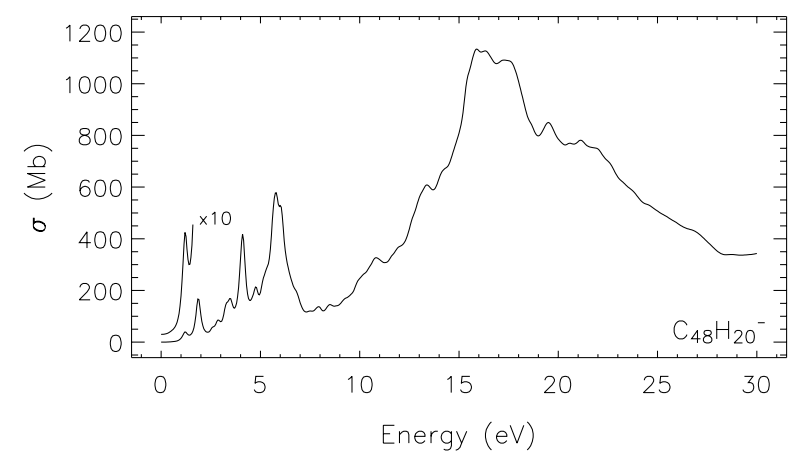

Fig. 23. Same as Fig. 2 for dicoronylene anion $\left(\mathrm{C}_{48} \mathrm{H}_{20}{ }^{-}\right)$.

the contribution of any given PAH will be by and large independent of its ionisation state. To elucidate this effect, Fig. 25 shows weighted averages of the electronic photo-absorption spectra of the same sample of PAHs, respectively in a neutral, cationic and anionic state. The average over a sample of molecules has the main effect of smoothing out the detailed structure resulting from the contribution of each single species. The three averaged spectra of neutral, cationic and anionic PAHs are almost indistinguishable. This confirms our previous conclusions in Malloci et al. (2004), extending them to anionic PAHs, namely: if any PAHs of small to medium size, be they neutral, cationic or anionic, are to account for the far-UV rise of the interstellar extinction curve they must also contribute to the short-wavelength side of the extinction bump at $\sim 2175 \AA$ (corresponding to $\sim 5.7 \mathrm{eV}$ ).
Table 2. Singlet $\pi^{*} \leftarrow \pi$ excitations of a subset of PAH anions in our sample. Our calculated excitation energies (in eV) and oscillator strengths (in parentheses) are compared to available experimental data as well as with published TD-DFT results. The direction of the transition dipole for each band is given according to the molecular geometries sketched in Fig. 1.

\begin{tabular}{cccc}
\hline \hline $\begin{array}{c}\text { Dipole } \\
\text { orientation }\end{array}$ & $\begin{array}{c}\text { This } \\
\text { work }\end{array}$ & $\begin{array}{c}\text { Published } \\
\text { theoretical }\end{array}$ & $\begin{array}{c}\text { Published } \\
\text { experimental }\end{array}$ \\
\hline \multicolumn{5}{c}{ Perylene anion $\left(\mathrm{C}_{20} \mathrm{H}_{12}{ }^{-}\right)$} \\
$x$ & $1.66(0.035)$ & $1.64(0.035)^{a}$ & - \\
$y$ & $2.32(0.381)$ & $2.26(0.333)^{a}$ & $2.23(/)^{b}$ \\
\hline \multicolumn{5}{c}{ Terrylene anion $\left(\mathrm{C}_{30} \mathrm{H}_{16}{ }^{-}\right)$} \\
$x$ & $1.61(0.035)$ & $1.59(0.029)^{a}$ & - \\
$y$ & $1.79(0.665)$ & $1.76(0.605)^{a}$ & $1.67(/)^{b}$ \\
\hline \multicolumn{5}{c}{ Quaterrylene anion $\left(\mathrm{C}_{40} \mathrm{H}_{20}{ }^{-}\right)$} \\
$y$ & $1.51(1.074)$ & $1.50(0.972)^{a}$ & $1.41(/)^{b}$ \\
$x$ & $1.52(0.029)$ & $1.56(0.025)^{a}$ & - \\
\hline
\end{tabular}

${ }^{a}$ TD-DFT calculations (BLYP/6-31G ${ }^{\star}$ ) by Halasinski et al. (2003).

${ }^{b}$ Neon matrix isolation spectroscopy data (Halasinski et al. 2003).

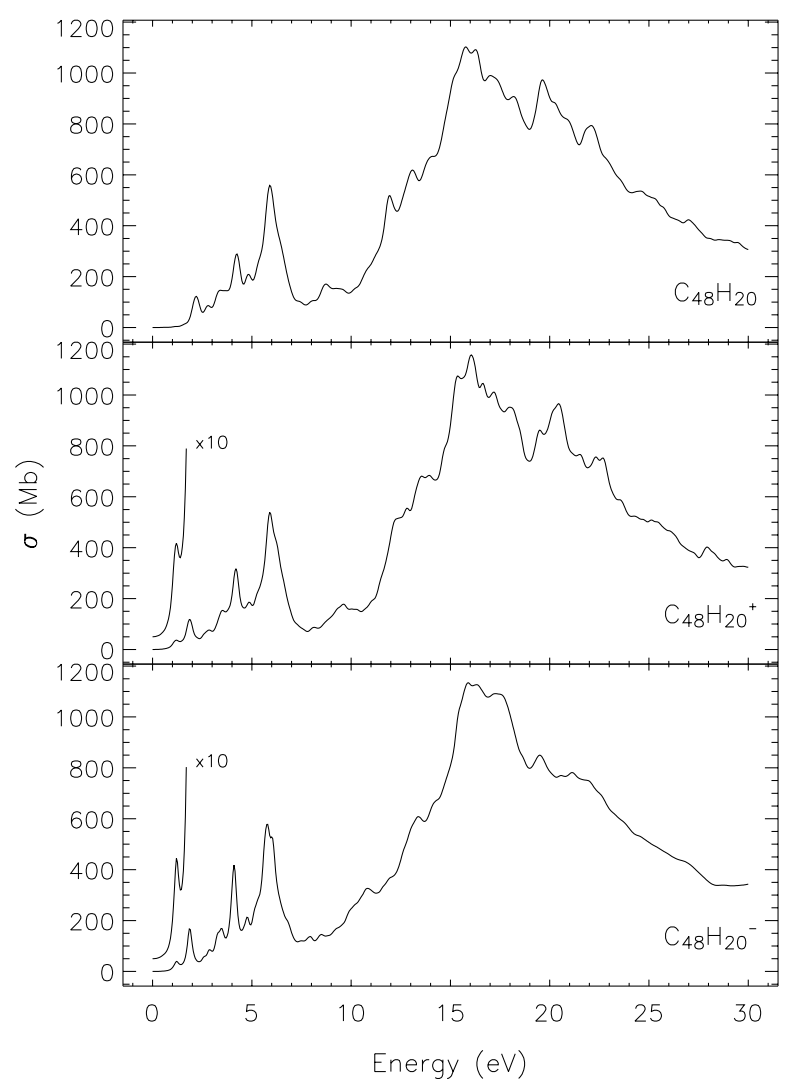

Fig. 24. Comparison between the photoabsorption cross-sections of dicoronylene $\left(\mathrm{C}_{48} \mathrm{H}_{20}\right)$ in neutral, cationic and anionic charge states.

\section{Conclusions}

Detailed information about the electron affinities of PAHs and the optical absorption properties of their mono-anions will enable one to model in a quantitative way the overall photophysics and ionisation balance of specific PAHs in many interstellar environments. Previous works have hypothesized that 


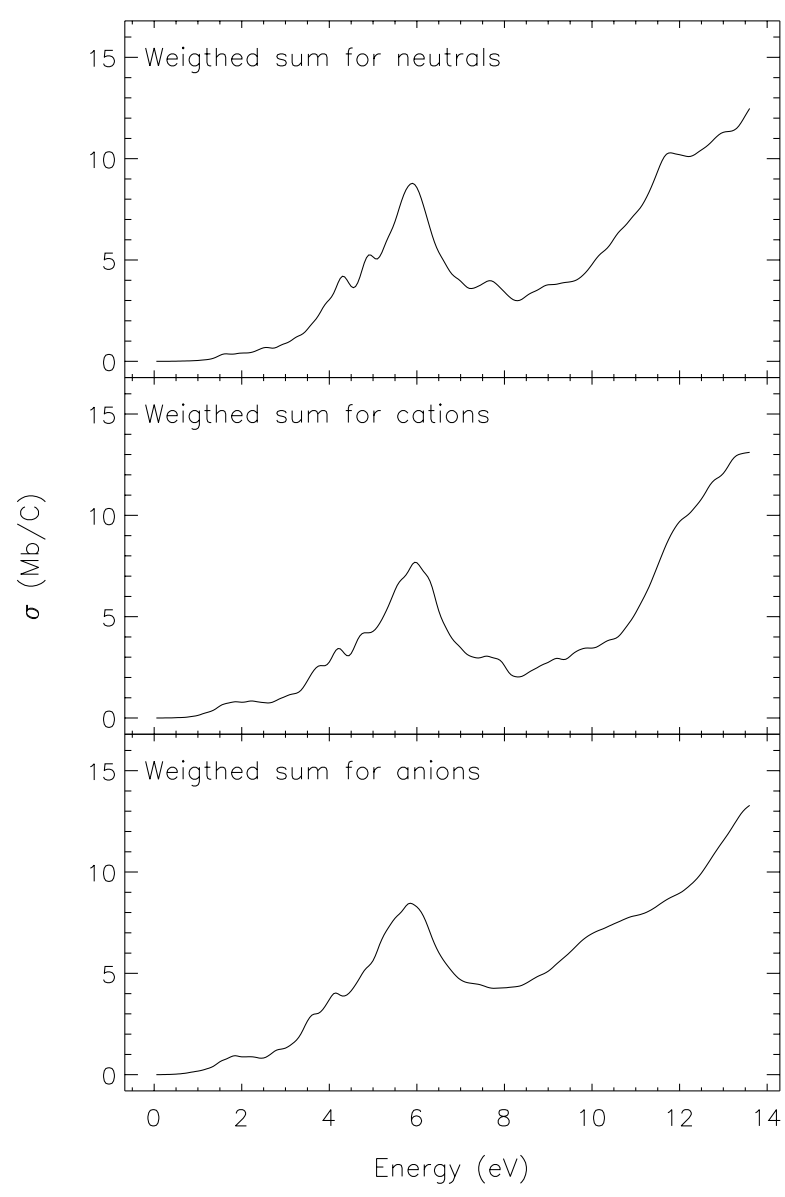

Fig. 25. Comparison between the weighted sum of the spectra displayed in Figs. 5-23, for both PAH neutrals (upper panel), the corresponding cations (middle panel) and the corresponding anions (lower panel). Statistical weights are simply assumed to be proportional to the inverse of the total number of carbon atoms $N_{\mathrm{C}}$ contained in each molecule. The average resulting from the sample considered is 24.26 .

PAHs containing more than $\sim 30$ carbon atoms ought to be largely singly negatively ionised in many interstellar environments. The individual data we present here on electron affinities and optical absorption spectra of an increasingly large sample of PAHs will enable the astrophysical community to significantly improve on such models.

This, in turn, will enable us to estimate the detailed IR emission spectrum of each species in each ionisation state, in a given interstellar environment (Mulas et al. 2004), for direct comparison with data from the ISO mission and, in the near future, from the Herschel mission. It will furthermore be possible to calculate the predicted rotational structure of specific electronic transitions of specific molecules, for comparison with very high resolution observations of Diffuse Interstellar Bands, as previously done for the cation of ovalene (Malloci et al. 2003).

Such tentative identifications will provide a guide for targeted laboratory measurements, which will still be needed to conclusively establish the presence of any specific $\mathrm{PAH}$ molecule in the interstellar medium.

Acknowledgements. G. Malloci gratefully acknowledges the financial support by INAF - Osservatorio Astronomico di Cagliari. We thank the authors of Octopus for their help on how to make the best use of their code. We acknowledge the High Performance Computational Chemistry Group for using their code: "NWChem, A Computational Chemistry Package for Parallel Computers, version 4.6" (2004), Pacific Northwest National Laboratory, Richland, Washington 99352-0999, USA. Part of the calculations presented here were performed within the "Iniziativa Trasversale Calcolo Parallelo dell'INFM".

\section{References}

Allamandola, L. J., Tielens, A. G. G. M., \& Barker, J. R. 1985, ApJ, 290, L25

Allamandola, L. J., Tielens, A. G. G. M., \& Barker, J. R. 1989, ApJS, 71,733

Allamandola, L. J., Hudgins, D. M., \& Sandford, S. A. 1999, ApJ, 511, L115

Bakes, E. L. O., \& Tielens, A. G. G. M. 1998, ApJ, 499, 258

Bakes, E. L. O., Tielens, A. G. G. M., \& Bauschlicher, C. W. 2001a, ApJ, 556, 501

Bakes, E. L. O., Tielens, A. G. G. M., Bauschlicher, C. W., Hudgins, D. M., \& Allamandola, L. J. 2001b, ApJ, 560, 261

Bakes, E. L. O., Bauschlicher, C. W., \& Tielens, A. 2004, in Astrophysics of Dust, ed. A. N. Witt, G. C. Clayton, \& B. T. Draine (San Francisco: ASP), ASP Conf. Ser., 309, 731

Barker, J. R. 1983, Chem. Phys., 77, 301

Bauschlicher, C. W. 2002, ApJ, 564, 782

Bauschlicher, C. W., \& Bakes, E. L. O. 2000, Chem. Phys., 262, 285

Bauschlicher, C. W., \& Bakes, E. L. O. 2001, Chem. Phys., 274, 11

Bauschlicher, C. W., \& Langhoff, S. R. 1997, Spectrochim. Acta Part A, 53, 1225

Becke, A. D. 1993, J. Chem. Phys., 98, 5648

Bernstein, M. P., Sandford, S. A., Allamandola, L. J., et al. 1999, Science, 283, 1135

Bernstein, M. P., Moore, M. H., Elsila, J. E., et al. 2003, ApJ, 582, L25

Boulanger, F. 1999, in Solid Interstellar Matter: The ISO Revolution, ed. L. d'Hendecourt, C. Joblin, \& A. Jones, Proc. Houches Workshop, February 2-6, 1998 (EDP Sciences and Springer-Verlag), 20

Burrow, P. D., Michejda, J. A., \& Jordan, K. D. 1987, J. Chem. Phys., 86,9

Ceperley, D. M., \& Alder, B. J. 1980, Phys. Rev. Lett., 45, 566

Crawford, M. K., Tielens, A. G. G. M., \& Allamandola, L. J. 1985, ApJ, 293, L45

Crocker, L., Wang, T. B., \& Kebarle, P. 1993, J. Am. Chem. Soc., 115, 7818

Dartois, E., \& d'Hendecourt, L. 1997, A\&A, 323, 534

Dessent, C. E. H. 2000, Chem. Phys. Lett., 330, 180

Draine, B. T. 2003, ARA\&A, 41, 241

Draine, B. T. 2004, in Astrophysics of Dust, ed. A. N. Witt, G. C. Clayton, \& B. T. Draine (San Francisco: ASP), ASP Conf. Ser., 309, 691

Du, P., Salama, F., \& Loew, G. H. 1993, Chem. Phys., 173, 421

Duley, W. W., \& Williams, D. A. 1981, MNRAS, 196, 269

Duncan, M. A., Knight, A. M., Negishi, Y., et al. 1999, Chem. Phys. Lett., 309, 49

Ehrenfreund, P. 1999, Science, 283, 1123

Foing, B. H., \& Ehrenfreund, P. 1994, Nature, 369, 296

Gonzales, J. M., Barden, C. J., Brown, S. T., et al. 2003, J. Am. Chem. Soc., 125, 1064

Gygax, R., Peters, H. L., \& Brauman, J. I. 1979, J. Am. Chem. Soc., 101, 2567 
Halasinski, T. M., Hudgins, D. M., Salama, F., Allamandola, L. J., \& Bally, T. 2000, J. Phys. Chem. A, 104, 7484

Halasinski, T. M., Weisman, J., Ruiterkamp, R., et al. 2003, J. Phys. Chem. A, 107, 3660

Heinze, H. H., Görling, A., \& Rösch, N. 2000, J. Chem. Phys., 113, 2088

Henning, T., \& Salama, F. 1998, Science, 282, 2204

Hirata, S., Head-Gordon, M., Szczepanski, J., \& Vala, M. 2003, J. Phys. Chem. A, 107, 4940

Hirata, S., Lee, T., \& Head-Gordon, M. 1999, J. Chem. Phys., 111, 8904

Hudgins, D. M., \& Allamandola, L. J. 2004, in Astrophysics of Dust, ed. A. N. Witt, G. C. Clayton, \& B. T. Draine (San Francisco: ASP), ASP Conf. Ser., 309, 665

Hudgins, D. M., Bauschlicher, C. W., \& Allamandola, L. J. 2001, Spectrochim. Acta Part A, 57, 907

Hudgins, D. M., Bauschlicher, C. W., Allamandola, L. J., \& Fetzer, J. C. 2000, J. Phys. Chem. A, 104, 3655

Joblin, C. 1992, Ph.D. Thesis, Université Paris 7

Joblin, C., Léger, A., \& Martin, P. 1992, ApJ, 393, L79

Joblin, C., Toublanc, D., Boissel, P., \& Tielens, A. G. G. M. 2002, Mol. Phys., 100, 3595

Kato, T., Yoshizawa, K., \& Yamabe, T. 1999, J. Chem. Phys., 110, 249

Kohn, W. 1999, Rev. Mod. Phys., 71, 1253

Langhoff, S. R. 1996, J. Phys. Chem, 100, 2819

Le Page, V., Snow, T. P., \& Bierbaum, V. M. 2001, ApJS, 132, 233

Le Page, V., Snow, T. P., \& Bierbaum, V. M. 2003, ApJ, 584, 316

Léger, A., \& d'Hendecourt, L. 1985, A\&A, 146, 81

Léger, A., d'Hendecourt, L., \& Defourneau, D. 1989, A\&A, 216, 148

Léger, A., \& Puget, J. L. 1984, A\&A, 137, L5

Lepp, S., \& Dalgarno, A. 1988, ApJ, 335, 769

Li, A. 2004, in Astrophysics of Dust, ed. A. N. Witt, G. C. Clayton, \& B. T. Draine (San Francisco: ASP), ASP Conf. Ser., 309, 417

Li, A., \& Greenberg, J. M. 1997, A\&A, 323, 566

Malloci, G., Mulas, G., \& Benvenuti, P. 2003, A\&A, 410, 623

Malloci, G., Mulas, G., \& Joblin, C. 2004, A\&A, 426, 105

Marques, M. A. L., Castro, A., Bertsch, G. F., \& Rubio, A. 2003, Computer Phys. Comm., 151, 60

Mulas, G. 1998, A\&A, 338, 243

Mulas, G., Malloci, G., \& Benvenuti, P. 2003, A\&A, 410, 639
Mulas, G., Malloci, G., Joblin, C., \& Toublanc, D. 2004, in preparation Omont, A. 1986, A\&A, 164, 159

Parac, M., \& Grimme, S. 2003, Chem. Phys., 292, 11

Perdew, J. P., \& Zunger, A. 1981, Phys. Rev. B, 23, 5048

Rienstra-Kiracofe, J. C., Barden, C. J., Brown, S. T., \& Schaefer III, H. F. 2001, J. Phys. Chem. A, 105, 524

Rienstra-Kiracofe, J. C., Tschumper, G. S., Schaefer III, H. F., Nandi, S., \& Ellison, G. B. 2002, Chem. Rev., 102, 231

Ruiterkamp, R., Halasinski, T., Salama, F., et al. 2002, A\&A, 390, 1153

Runge, E., \& Gross, E. K. U. 1984, Phys. Rev. Lett., 52, 997

Salama, F. 1999, in Solid Interstellar Matter: The ISO Revolution, ed. L. d'Hendecourt, C. Joblin, \& A. Jones, Proc. Les Houches Workshop, February 2-6, 1998 (EDP Sciences and Springer-Verlag), 65

Salama, F., Bakes, E. L. O., Allamandola, L. J., \& Tielens, A. G. G. M. 1996, ApJ, 458, 621

Salama, F., Galazutdinov, G. A., Krełowski, J., Allamandola, L. J., \& Musaev, F. A. 1999, ApJ, 526, 265

Schiedt, J., Knott, W., Le Barbu, K., Schlag, E., \& Weinkauf, R. 2000, J. Chem. Phys., 113, 9470

Schiedt, J., \& Weinkauf, R. 1997a, Chem. Phys. Lett., 266, 201

Schiedt, J., \& Weinkauf, R. 1997b, Chem. Phys. Lett., 274, 18

Shida, T., \& Iwata, S. 1973, J. Am. Chem. Soc., 95, 3473

Straatsma, T. P., Apra, E., Windus, T. L., et al. 2003, NWChem, A Computational Chemistry Package for Parallel Computers, Version 4.5

Szczepanski, J., Wehlburg, C., \& Vala, M. 1995, Chem. Phys. Lett., 232, 221

Treitel, N., Shenhar, R., Aprahamian, I., Sheradsky, T., \& Rabinovitz, M. 2004, Phys. Chem. Chem. Phys., 6, 1113

Tulej, M., Kirkwood, D. A., Pachkov, M., \& Maier, J. P. 1998, ApJ, 506, L69

van der Zwet, G. P., \& Allamandola, L. 1985, A\&A, 146, 76

Vijh, U. P., Witt, A. N., \& Gordon, K. D. 2004, ApJ, 606, L65

Weisman, J. L., Lee, T. J., \& Head-Gordon, M. 2001, Spectrochim. Acta Part A, 57, 931

Weisman, J. L., Lee, T. J., Salama, F., \& Head-Gordon, M. 2003, ApJ, 587, 256

Yabana, K., \& Bertsch, G. F. 1999, Int. J. Quant. Chem., 75, 55 